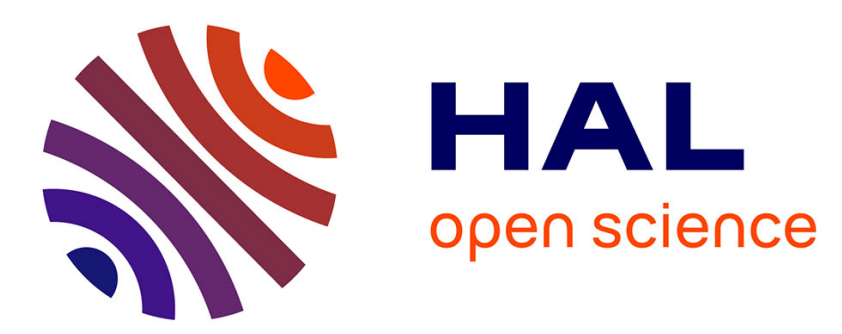

\title{
Development of an in-plane biaxial test for forming limit curve (FLC) characterization of metallic sheets
}

Ibrahim Zidane, Dominique Guines, Lionel Leotoing, Eric Ragneau

\section{To cite this version:}

Ibrahim Zidane, Dominique Guines, Lionel Leotoing, Eric Ragneau. Development of an in-plane biaxial test for forming limit curve (FLC) characterization of metallic sheets. Measurement Science and Technology, 2010, 21, pp.1-11. 10.1088/0957-0233/21/5/055701 . hal-00981719

\section{HAL Id: hal-00981719 \\ https://hal.science/hal-00981719}

Submitted on 22 Apr 2014

HAL is a multi-disciplinary open access archive for the deposit and dissemination of scientific research documents, whether they are published or not. The documents may come from teaching and research institutions in France or abroad, or from public or private research centers.
L'archive ouverte pluridisciplinaire HAL, est destinée au dépôt et à la diffusion de documents scientifiques de niveau recherche, publiés ou non, émanant des établissements d'enseignement et de recherche français ou étrangers, des laboratoires publics ou privés. 


\title{
Development of an in-plane biaxial test for FLC characterization of metallic sheets
}

\author{
I. Zidane, D. Guines, L. Léotoing, E. Ragneau \\ Université Européenne de Bretagne, France, INSA-LGCGM - EA 3913, \\ 20, avenue des Buttes de Coësmes 35043 RENNES Cédex \\ E-mail: dominique.guines@insa-rennes.fr
}

\begin{abstract}
The main objective of this work is to propose a new experimental device able to give for a single specimen a good prediction of rheological parameters and formability under static and dynamic conditions (for intermediate strain rates). In this paper, we focus on the characterization of sheet metal forming. The proposed device is a servo-hydraulic testing machine provided with four independent dynamic actuators allowing biaxial tensile tests on cruciform specimens. The formability is evaluated thanks to the classical forming limit diagram (FLD) and one of the difficulties of this study was the design of a dedicated specimen for which the necking phenomenon appears in its central zone. If necking is located in the central zone of the specimen, then the speed ratio between the two axes controls the strain path in this zone and a whole forming limit curve can be covered. Such a specimen is proposed through a numerical and experimental validation procedure. A rigorous procedure for the detection of numerical and experimental forming strains is also presented. Finally, an experimental forming limit curved is determined and validated for an aluminium alloy dedicated to the sheet forming processes (AA5086).
\end{abstract}

Keywords: biaxial tensile test, cruciform specimens, forming limit diagram (FLD), dynamic tests, Digital Image Correlation (DIC)

Submitted to: Meas. Sci. Technol.

\section{Introduction}

Sheet metal forming is one of the most common metal processing operation. More and more precision is required relatively to both the geometry and the mechanical properties of the final product. For this reason, the traditional trial-and-error method of optimizing such metal forming operations is apparently inefficient. Also, the modelling of material behavior is a very efficient way of reducing the time and costs involved in optimizing manufacturing processes. Simulation of sheet metal forming, mainly based on finite element (FE) modelling, requires to know precisely the constitutive law and formability limits of the material. These material properties have to be characterized 
at strain, strain rate and temperature ranges corresponding to forming processes. As most metal forming operations are carried out under biaxial states of stress, limiting the evaluation of material's mechanical characteristics to uniaxial tensile tests can lead to a misrepresentation of the behavior of the material. The use of more realistic loading during the test such as the introduction of biaxial loading conditions leads to a more accurate representation of the expected behavior of the material by considering precisely anisotropy effects, for example.

The general purpose of this work is to propose an experimental test and the associated specimen shape for determining the whole elasto-plastic behavior of metallic sheets including hardening, anisotropic behavior and formability limits. As explained above, to be in accordance with operating conditions encountered in metal forming processes, theses characterizations must be performed for biaxial loadings and for large ranges of strain rate and temperature. At the present time, the identification of hardening parameters under mono-axial, static or dynamic loadings are classically performed by means of numerical modelling used with optimization methods in the so-called inverse analysis procedure ([1], [2]). This paper focuses on the development of both an experimental test and the associated specimen shape appropriate for the determination of a whole forming limit curve for static loadings.

A well-known method of describing the formability of materials is the forming limit diagram (FLD). In FLDs, a FLC (Forming Limit Curve) represents a plot of major and minor available principal strains in the plane of the deformed sheet corresponding to the occurrence of the necking. The FLD determination is usually obtained from static conventional tests (Marciniak test [3], Nakazima test [4] or bulge test [5]). In such tests, only linear strain paths (ratio between major and minor strains) can be realized. The paths are defined from the specimen or tool geometry and many different specimens are required to cover the whole forming limit curve. Depending on the considered test, the friction effect between the specimen and the tool can influence the prediction of the material formability and it is still a difficulty to evaluate the coefficient friction value. Moreover, strain-rate sensitivity has been identified as an important factor determining formability of sheet metal and can alter substantially the level and the shape of FLCs. A review of currently available literature shows that relatively little attention has been paid to models taking strain rate into account. Analytically, the strain rate sensitivity has been studied mainly through the classical M-K model [6]. In these analytical models, the strain hardening behavior and the strain rate sensitivity of materials are generally represented by simplistic power laws. But it has been shown that these simplistic laws are not well adapted, especially for aluminium alloys, and only permit the study of the influence of the strain rate sensitivity index but not the influence of the value of the strain rate and temperature [7]. Experimentally, it is relatively difficult to adapt the conventional tests to dynamic loadings due to the dynamic response of the whole testing devices. Very few experimental data are available and no correlations have been presented between experimental results and those of numerical or analytical predictive models of FLCs. 
In order to overcome the drawbacks of the above mentioned tests, a cruciform specimen could be an interesting alternative if the strain path at the onset of necking is directly imposed by the control of the testing machine, independently from the specimen shape. Moreover, for such specimen, the friction cannot alter both formability and strain path. Nevertheless, this kind of specimen has never been used in formability studies even if many authors intensively used it for other mechanical characterizations (fatigue [8], creep [9] or yield criteria and hardening laws [10]). Although cruciform specimens have been investigated quite extensively, no standard geometry exists to this day [11] and the design of the specimen shape is still the main difficulty that restricts applications for the cruciform biaxial tensile test.

The developed test machines to produce biaxial loading on cruciform specimen are either stand-alone biaxial testing machines or link mechanism attachments for biaxial testing. The device designed by Makinde et al. [12] consisted of four hydraulic actuators with a capacity of $250 \mathrm{kN}$. Two actuators were used on each axis to ensure that the center of the specimen did not move during testing. The results from this research were used to develop an optimum specimen for low strains. Using the same testing apparatus Green et al. [13] have investigated the elasto-plastic behaviour of an 1145 aluminium sheet alloy. Flat cruciform specimens have been tested under in-plane biaxial loading conditions to obtain both the plastic work contours and the biaxial flow curves. A biaxial extensometer is used to measure and control the strains in the central area of the specimen along each loading direction. A finite element analysis of each test was carried out. The numerical FE modeling ensure that the computed force in the arms versus strain in the center of the sample curves coincide with the corresponding experimental ones. Thus the parameters of the four different phenomenological models of anisotropic plasticity and biaxial flow curves are determined. A further stand-alone device developed by Boehler et al. [14] consisted of four double acting screw driven pistons, mounted on an octogonal vertical frame. The test speed varies between 0.003 and $0.3 \mathrm{~mm} / \mathrm{min}$. This machine was used to test various cruciform specimen types to develop an optimum specimen design. The optimized specimen is performed to identify anisotropic elastic behaviour. Kuwabara et al. [15] study the elastic and plastic deformation behavior of cold rolled low-carbon steel under biaxial tension. The biaxial tester was a servo type and opposing hydraulic cylinders were connected to common hydraulic lines so that the same hydraulic pressure was applied to each. A load cell was used in each direction to calculate the stress in the specimen. The strain was calculated using strain gauges placed in the gauge section of the specimen. The flow stresses measured were in relatively good agreement with those predicted by Hosford's yield criterion. Naumenko and Atkins [16] performed biaxial tensile tests on pre-cracked high-strength low-hardening aluminium specimens. They demonstrated that the effect of biaxiality loading on the crack extension resistance $R$, was unexpectedly strong. Shimamoto et al. [17] have developed a hydraulic biaxial testing system to perform both dynamic and static tests. From dynamic tests, they investigate the crack extension behavior on an aluminium alloy $(\mathrm{A} 7075-\mathrm{T} 6)$ at $1000 \mathrm{~mm} / \mathrm{s}$. In an attempt to reduce the 
cost associated with building stand-alone test machines, standard tensile or compressive testers have been converted to biaxial test setup (Hoferlin et al. [18], Mohr and Mulalo [19], Ferron and Makinde [20]). Nevertheless, link mechanism attachments for biaxial testing machines seem not very efficient to study the forming limits under various and complex loading paths which would require to change the geometry of the system (length of links, ...) for each path. Moreover, in such experimental devices, both high stiffness and natural frequencies are expected so these systems are not appropriate for biaxial tests and particularly dynamic ones. Stand-alone testing machines seem to be more appropriated to realize biaxial tests and more particularly to obtain different strain paths or various stress states of biaxial tension by changing the proportion of loads or displacements of the two axes. Moreover, to perform both static and dynamic tests with the same device, hydraulic technology seems more appropriated, by using pump pressure or accumulator pressure for static tests and instantaneously releasing a great quantity of high-pressure flow accumulated for dynamic tests.

In this work, a servo-hydraulic testing machine provided with four independent dynamic actuators has been used. The testing device is in a horizontal configuration which facilitates access for an easy setting of the specimen and allows a good followup of the central zone throughout the test by video recording. The center point of the specimen is always maintained stationary throughout the test by an efficient servohydraulic control. In order to determine the forming limits under complex loading paths, a specimen shape has to be defined. The main difficulty to design an appropriate cruciform specimen shape consists in forcing the onset of necking in the central zone and not on the arms of the specimen. Moreover, for dynamic tests, the maximum stiffness of the specimen, the initial one, has to be adjusted according to the experimental setup capacities in order to control tensile test velocities. For the considered experimental device, the stiffness of the specimens should not exceed $45 \mathrm{kN} / \mathrm{mm}$ for dynamic tests. Others considerations like manufacturing constraints must also be taken into account.

In this study, different specimen shapes used in previous works are numerically investigated through FE simulations. A modified cruciform specimen shape is then proposed and the best set of geometrical dimensions is defined from a parametric study. The proposed specimen shape is then numerically validated. Finally, the characteristics of the developed biaxial system are presented and experiments are conducted on the proposed cruciform specimen shape. The efficiency of the proposed specimen shape is also validated by experiments. The central area of the cruciform specimen is filmed by a camera and strain fields are determined by means of an image correlation technique. For different strain paths, experimental results, i.e., the strain level at the onset of necking from the cruciform specimen are compared with those of the more conventional Marciniak test. 


\section{Specimen design}

To characterize the mechanical behavior of materials subjected to biaxial loadings, various cruciform specimens have been defined. Hannon and Tiernan have published a complete review on this subject [21]. Several researchers $([22],[9])$ have proposed a cruciform specimen shape with a reduced thickness square central zone and grooves in the arms. An example of such geometry is shown on Figure 1.

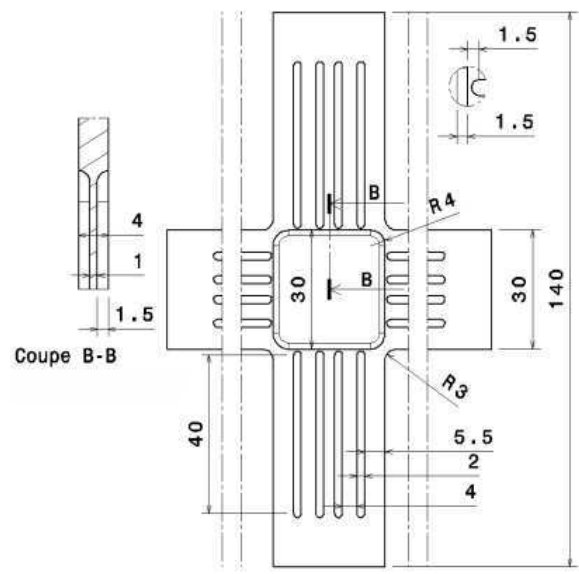

Figure 1. Geometry of Specimen 1.

To study the influence of biaxial loadings on hardening anisotropic materials, Ferron and Makinde [20] and Demmerle and Boehler [23] have optimized this specimen and obtained an homogeneous stress-strain field over a large part of the square zone. Johnston et al. [24] modified the specimen 1 and added a circular central zone with a smaller thickness (Figure 2).

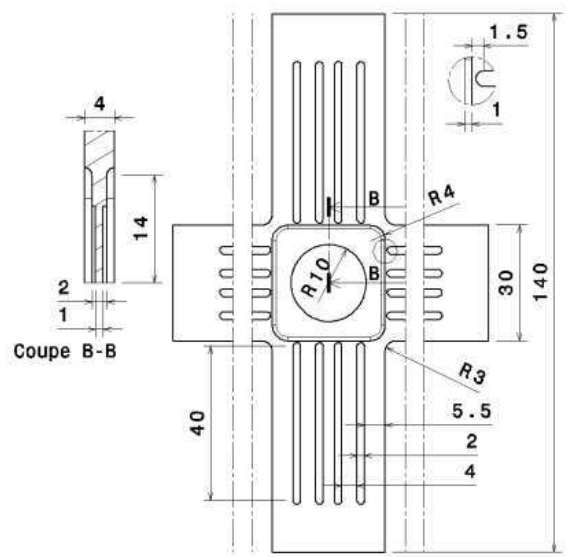

Figure 2. Geometry of Specimen 2.

Removing arm grooves, Yong et al. [25] proposed the shape shown Figure 3. This form has been developed to determine the FLD under complex loading paths 
by numerical finite element simulations. The initial specimen dimensions defined by the authors lead to a very stiff specimen: the arm width is $90 \mathrm{~mm}$ and the central area diameter is $20 \mathrm{~mm}$. But to date, to our knowledge, no experimental results were published to validate this shape.

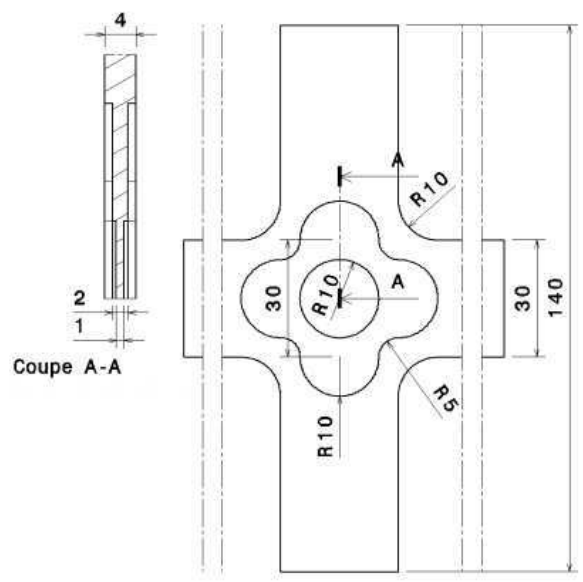

Figure 3. Geometry of Specimen 3.

Another cruciform specimen shape (Figure 4) with a reduced thickness in the central area and variable width arms has been proposed by Zhang and Sakane [26]. This specimen has been used to realize fatigue tests, i.e. at low strain levels.

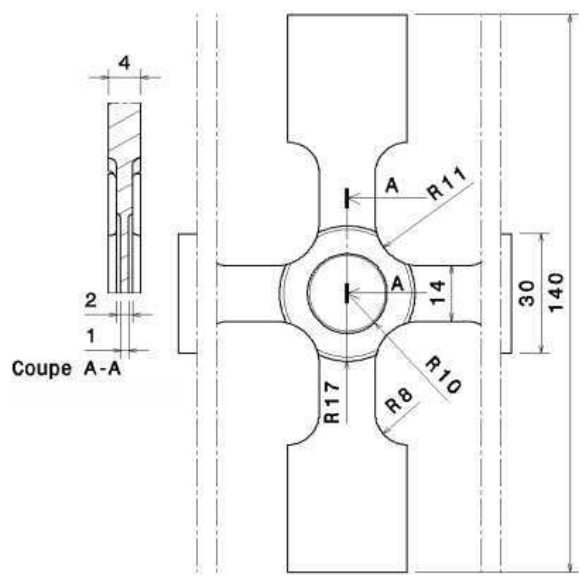

Figure 4. Geometry of Specimen 4.

\subsection{Numerical investigations}

Through FE simulations, the efficiency of the four various specimen shapes mentioned above is numerically investigated. For that, equi-biaxial tensile test is simulated by means of the FE software package ABAQUS. Considering the symmetry of the specimen geometry, only one quarter of the specimen is analyzed. For meshing, tetrahedron 
elements are used and a refined mesh is adopted in the sensitive areas where strain localizations could occur (central zone, intermediate section, fillet, grooves). The isotropic elasto-plastic behavior of an aluminium alloy is assumed. The elastic part is described by Hooke's model with Young modulus, $E=70000 M P a$ and Poisson ratio, $\nu=0.3$. For the plastic part, isotropic von Mises yield criteria is used and the hardening behavior is described by a Ludwick's law:

$$
\bar{\sigma}=\bar{\sigma}_{0}+\mathrm{K} \bar{\varepsilon}^{\mathrm{n}}
$$

where $\bar{\sigma}$ and $\bar{\varepsilon}$ are the equivalent stress and the equivalent plastic strain respectively, $\bar{\sigma}_{0}$ is the Yield stress obtained from a mono-axial tensile test, $K=553 \mathrm{MPa}$ and $n=0.61$ are material parameters.

The various shapes suggested (figures 1 to 4 ) were dimensioned with the following rules: (i) the characteristic dimension of the central zone is fixed at a value ranging from 20 to $30 \mathrm{~mm}$. This dimension is mainly imposed by the dynamic acquisition capacities of the camera, (ii) other principal dimensions (width and thickness of the arms, thickness of the central area) are chosen according to either the maximum load capacities of the experimental setup or the maximum stiffness of the sample. The maximum value of the stiffness is defined by the capacities of the experimental device. Consequently, the thickness of the central area and arms are respectively fixed to 1 and $4 \mathrm{~mm}$. For specimens 2 to 4 , the thickness of the intermediate zone is $2 \mathrm{~mm}$.

\subsection{Results and discussion}

To ensure that necking always appears in the central zone, the design of the cruciform specimens must induce the greatest deformations in the central zone and no strain localizations in the other areas (grooves, fillets, ...). Both the equivalent plastic strain and the maximal principal strain in the specimen are observed. In the geometrical singularities (grooves for example), the observation of the equivalent plastic strain is not sufficient, since the major principal strain can reach high values leading to a localization of the deformation (and then fracture) although the equivalent strain is not very high. The figures 5 and 6 show the distribution of the equivalent plastic strain (PEEQ) and the maximal principal strain fields for specimens 1 to 4 . Only the interesting zone, i.e. the central zone is observed. All the results presented correspond to the moment when the maximum value of the equivalent plastic strain reaches $30 \%$ in one point of the specimen. In order to evaluate the influence of the shape details such as the grooves, the fillet of the arms, the evolution of the strains (equivalent plastic and maximal principal) is also plotted along a path (represented by a mixed line).

According to figures 5 and 6 , one can see that the strain concentration is more homogeneous in the central test section of the specimens with grooves (specimens 1 and 2 ). But, for the specimen 1 , the maximum strain value $(30 \%)$ is reached in the grooves. This phenomenon is less pronounced for specimen 2 where an intermediate zone has been added. The equivalent plastic strain is then slightly higher in the central zone 


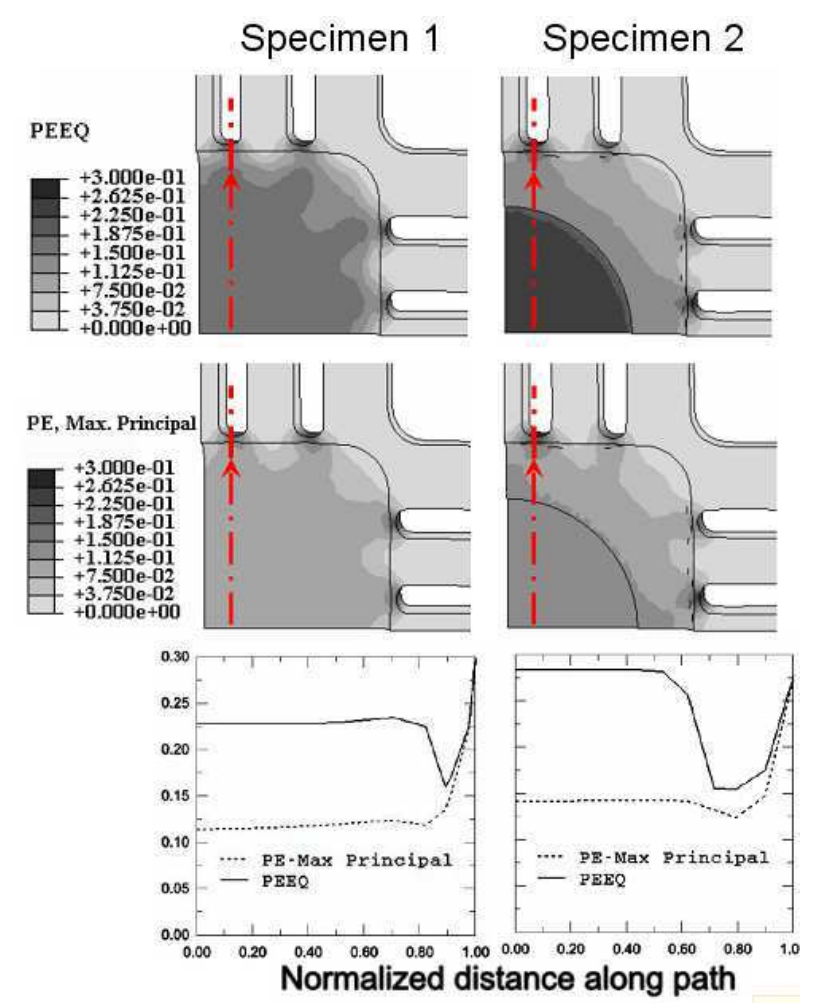

Figure 5. Equivalent plastic strain and maximal principal strain fields for specimens 1 and 2 .

than in the grooves. But, the maximal principal strain is always much higher $(27.5 \%)$ in grooves than in the central area (15\%). For the specimen 3, the maximal principal strain is obtained in the fillet of the arms $(25 \%)$ whereas in the central zone the level reached is approximately $15 \%$. For the specimen 4 , the highest strain values (maximal principal strain or equivalent plastic strain) are located in the fillet of the arms whereas in the central area, the value of the maximum principal strain is the lowest one among the four specimens $(11 \%)$.

Table 1. Stiffnesses of the tested specimens.

\begin{tabular}{ccccc}
\hline Specimen & 1 & 2 & 3 & 4 \\
\hline Stiffness $(\mathrm{KN} / \mathrm{mm})$ & 42 & 45 & 62 & 38 \\
\hline
\end{tabular}

The results of the FE simulations show that the specimens 2 and 3 seem to be the more efficient since they lead to the maximum values of strain in the central zone. But specimen 3 is, for all the specimens tested, the stiffest (Tab. 1). Moreover, for all the specimens, to reduce the stress/strain concentrations in the fillets of the arms, it would be advisable to increase the width of the arms but that would result in increasing significantly the stiffness of the specimen. Finally, the shape of specimen proposed figure 2 seems to be the most effective and the most promising. The positioning of the grooves on the arms permits to limit the stiffness of the specimen. An optimization can 


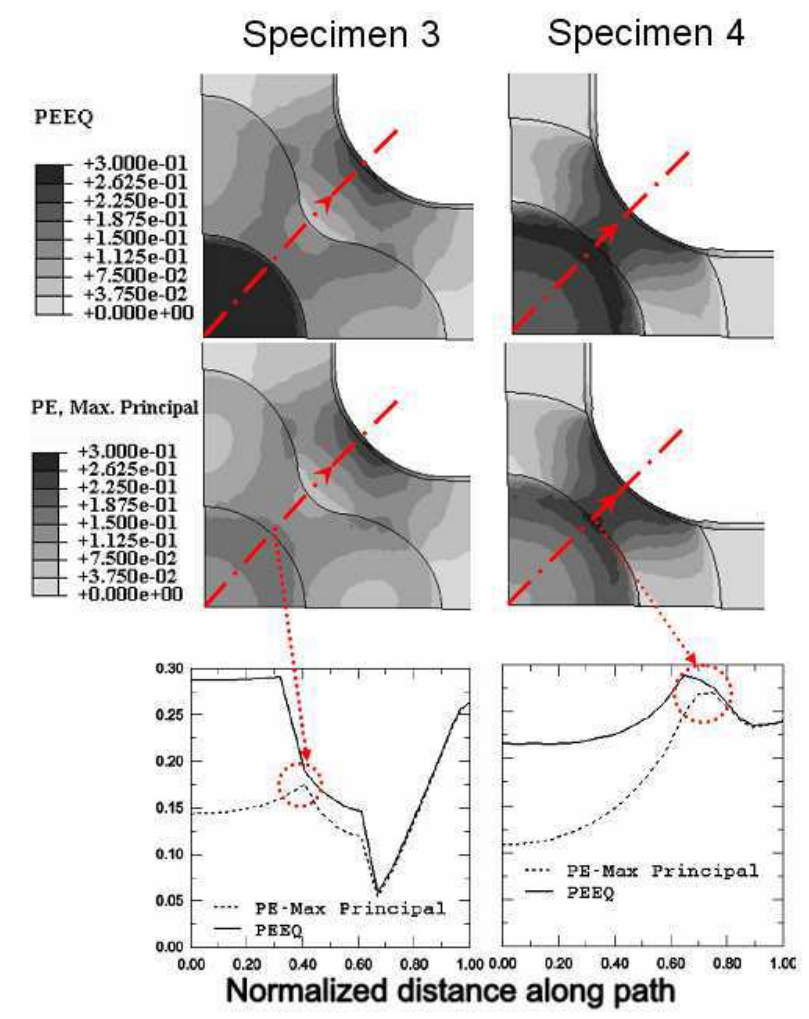

Figure 6. Equivalent plastic strain and maximal principal strain fields for specimens 3 and 4.

be performed, FE simulations show notably that the distance between the ends of the grooves and the edge of the square central zone, had a great influence on the level of deformation in the grooves and fillets of the arms. Thereafter, on the basis of the shape of the sample 2, a modified form is proposed and optimized in order to reduce the strain localization in grooves.

\section{Specimen optimization}

The specimen chosen in the previous part must be optimized in order to make efficient its use for a whole forming limit curve identification. Finally, the validity of the optimization is verified with the determination of a numerical FLC for the above used material.

\subsection{Optimization of the cruciform specimen shape}

The main purpose of the optimization is to ensure a strain localization at the central point of the specimen and then the onset of necking in this zone. The strain path value at the central point of the specimen is directly linked to the velocity ratio of actuators for the two tested axes. If the strain localization appears in a different zone, the strain path in this zone will be different from the velocity ratio and then only a partial forming 
limit curve will be drawn. Thereafter on the basis of the shape illustrated by figure 7 , a modification of the form of the central zone is proposed.

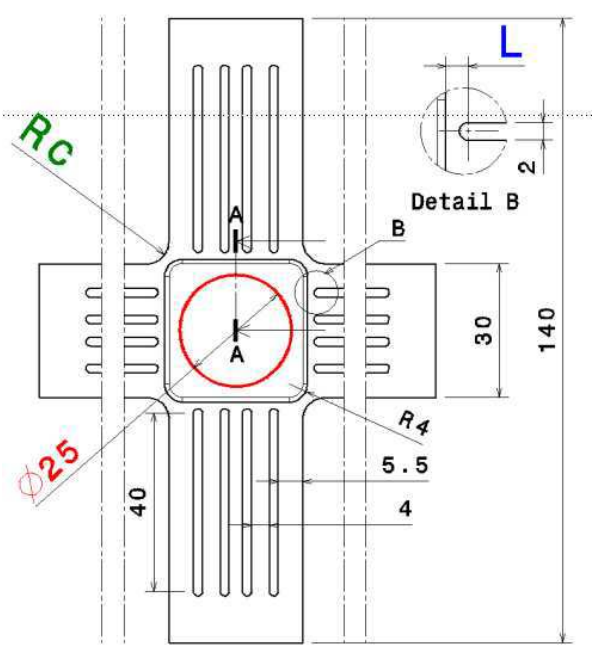

Figure 7. Geometry of the optimized specimen shape.

According to the previous study, two key geometrical parameters have been identified for the strain distribution in the specimen. These parameters are the length $L$ between the ends of the grooves and the edge of the square central zone and the fillet of arms $R_{c}$ (Figure 7). As seen before, by adjusting these parameters to adequate values, the strain level in grooves and fillets of the arms is limited by comparison with the level in the central region of the specimen. This is the first step of the optimization procedure, the second step consists in the strain localization at the central point of the specimen for the strain path control. Hereafter, to achieve the procedure, two different shapes are proposed and discussed for the central zone of the specimen. For specimen I, a chamfer between the flat central circular zone and the intermediate square zone is defined (Figure 8) and for specimen II, the central point and the intermediate square zone are connected by a curved profile (radius) (Figure 9).

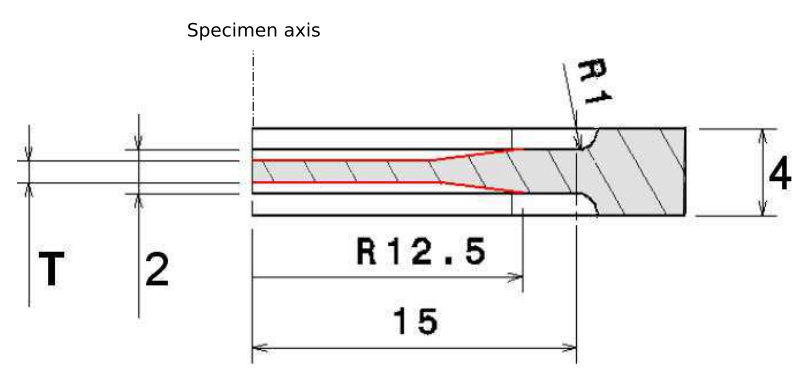

Figure 8. Specimen I : transition with chamfer.

One can see in figures 8 and 9 that the thickness of the central test section $T$ is also a key parameter for the strain localisation and homogeneity. For specimen I, the 


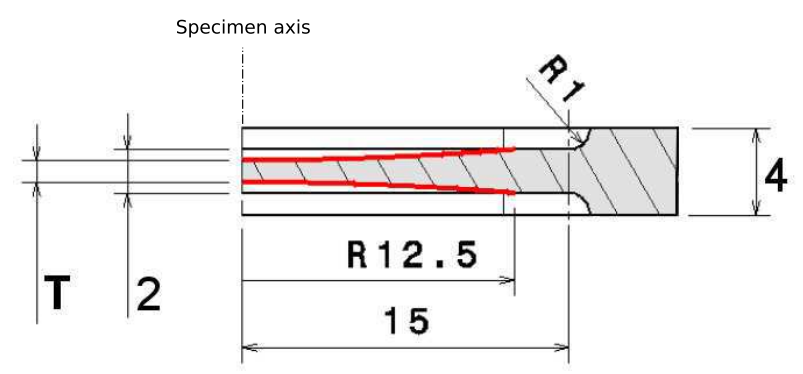

Figure 9. Specimen II : transition with radius.

diameter of the flat central test section is noted $D_{i}$. A parametric study was carried out and the best set of parameters obtained is given in table 2 .

Table 2. Optimized geometrical parameters.

\begin{tabular}{ccccc}
\hline & $L(\mathrm{~mm})$ & $R_{c}(\mathrm{~mm})$ & $D_{i}(\mathrm{~mm})$ & $T(\mathrm{~mm})$ \\
\hline Specimen I & 4.5 & 8 & 10 & 0.75 \\
Specimen II & 4.5 & 8 & - & 0.75 \\
\hline
\end{tabular}

In order to make a choice between specimen I and specimen II, we can observe the evolution of strain path in the two specimens (Figure 10) for equi-biaxial conditions, i.e. same imposed velocities for the two axes.

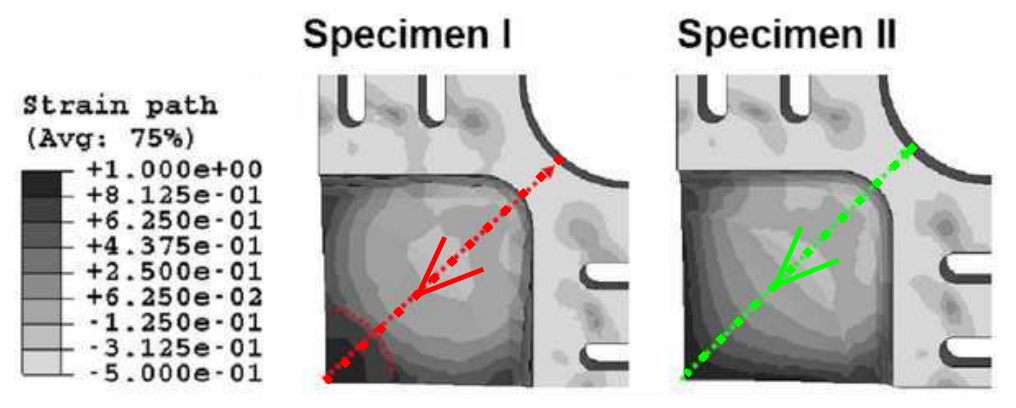

Figure 10. Strain path distribution in specimen I and II.

A strain path value of 1 is logically observed at the central point of the two specimens but strain localization and then the necking phenomenon doesn't necessary appear in this zone. To identify the zone where necking is likely to appear, the evolution of equivalent plastic strain is plotted following the diagonal line of the square central zone (dotted lines in Figure 10) just before the onset of necking.

Two different evolutions of the equivalent plastic strain can be observed in Figure 11. For specimen II, the maximum value is measured at the central point of the specimen and the strain path corresponds to the imposed velocity ratio. However, for specimen I, the maximum value of equivalent plastic strain is reached in the transition zone between chamfer and flat central zone. In this zone, a strain path of 0.6 is evaluated. As a result, if necking appears in this zone, the strain path is not directly imposed 


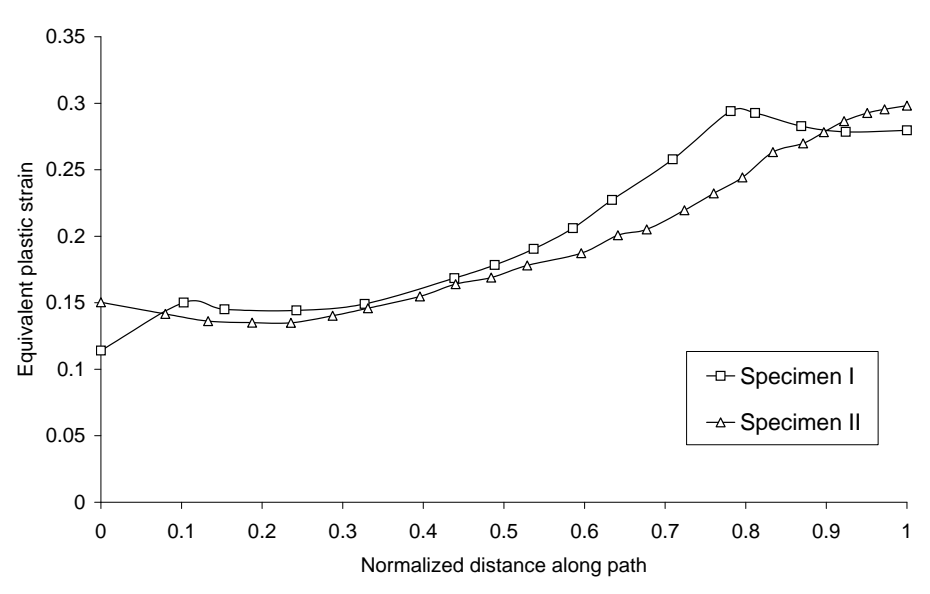

Figure 11. Evolution of the plastic equivalent strain on the diagonal line of specimen I and II square central zone.

by the displacement conditions (ratio of 1 ) and the construction of the whole forming limit curve becomes impossible in the expansion domain (strain path from 0 to 1 ). This result is confirmed by figure 12 in which we can observe the evolution of strain path for different speed ratios at the central point for specimen II and at the transition zone for specimen I. As previously stated, specimen II is more appropriate to cover the whole strain path range. Besides, at the end of the test, for the onset of necking, the strain path remains constant for all speed ratios for this specimen.
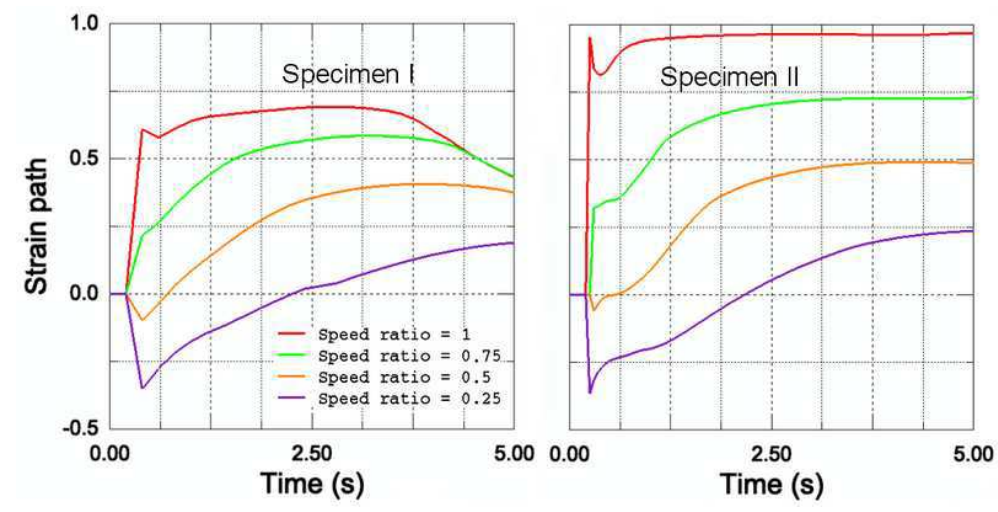

Figure 12. Strain paths in specimens I and II for different imposed velocity ratios.

In conclusion, specimen II seems to be appropriate for a complete characterization of sheet formability. This is confirmed by the following part in which a numerical forming limit curve can be found by use of this specimen. 


\subsection{FLC identification}

For the numerical identification of forming limit curves, the main difficulty lies in the choice of an appropriate criterion to detect the onset of necking. Different failure criteria have been discussed by Zhang et al [7]. If the necking occurs in a zone, a sharp change of strain can be observed, corresponding to the onset of a plastic instability. Moreover, after the onset of this phenomenon, the level of strain remains constant in the other adjacent zones. This behaviour can be observed by following the evolution of the equivalent plastic strain for four different nodes, from the specimen central point (node 1) (Figure $13)$.

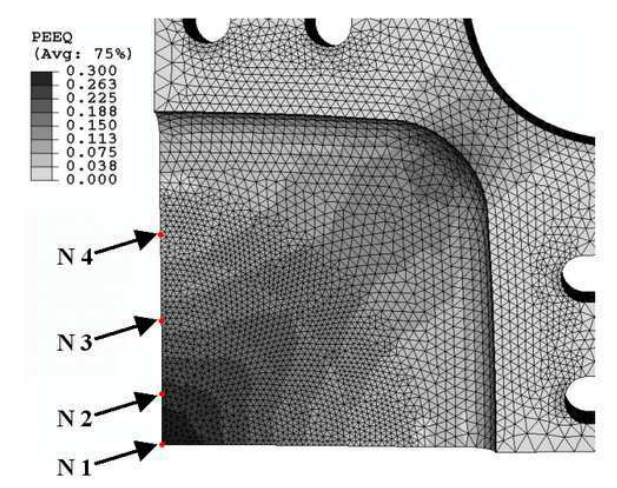

Figure 13. Localization of nodes 1 to 4 in the central zone of the specimen.

The evolution of the equivalent plastic strain for nodes 1 to 4 is plotted in Figure 14 for equi-biaxial conditions. An homogeneous evolution for these four curves is observed up to a moment of about $t=3.5 \mathrm{~s}$, after which the equivalent plastic strain for node 1 diverges rapidly compared to that of nodes 3 and 4 . As expected, for these two nodes, the equivalent plastic strain remains constant after the onset of necking in the zone of node 1. Moreover, this observation confirms the efficiency of specimen II in localizing necking at its center.

In this work, the criterion widely used in the M-K model studies is chosen to predict the onset of localized necking. When the equivalent plastic strain increment ratio between a point located in the necking zone (node 1) and a point in a adjacent zone (nodes 3 or 4) attains a critical value, the onset of localized necking is assumed to occur and the corresponding major and minor strains calculated at node 1 are retained as a point on the FLC. In the literature, this critical value generally varies from 7 [27] to 10 [28] and it is necessary to rigorously fix it for our specific geometry. From Figure 14 , the plastic instability is clearly located with the evolution of the equivalent plastic strain at node 1 thanks to the onset of a bifurcation point at $t_{\text {Bifurcation }}=3.4 \mathrm{~s}$. We propose to plot the evolution of the equivalent plastic strain increment ratio between nodes 1 and $3\left(\Delta \bar{\varepsilon}^{1} / \Delta \bar{\varepsilon}^{3}\right)$ and between nodes 1 and $4\left(\Delta \bar{\varepsilon}^{1} / \Delta \bar{\varepsilon}^{4}\right)$. In order to apply this method for experimental identification of forming limit curves, the increment must not be calculated for a short time, otherwise many fluctuations associated with the accuracy 


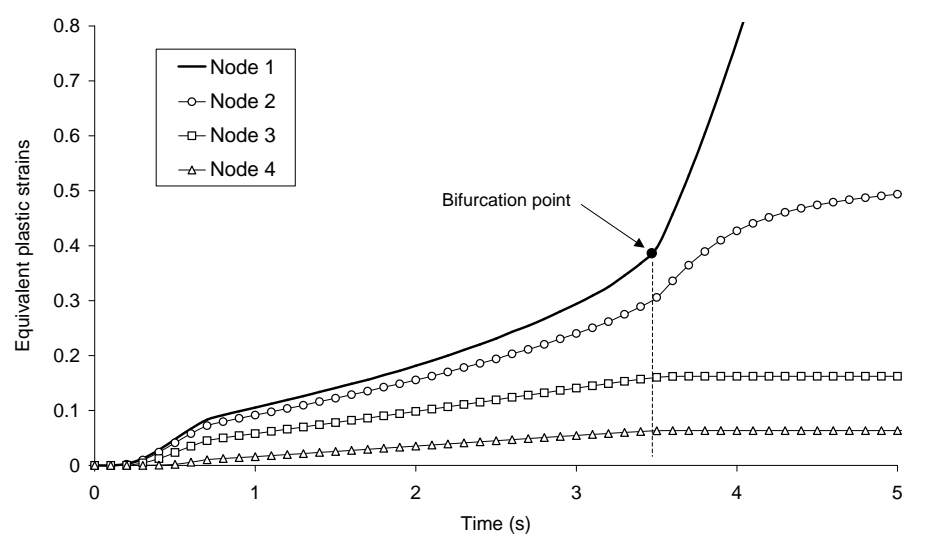

Figure 14. Evolution of the equivalent plastic strain for nodes 1 to 4 .

of the experimental strain measurement could appear. The increment is calculated for a time of $1 s$ and the results are plotted in Figure 15.

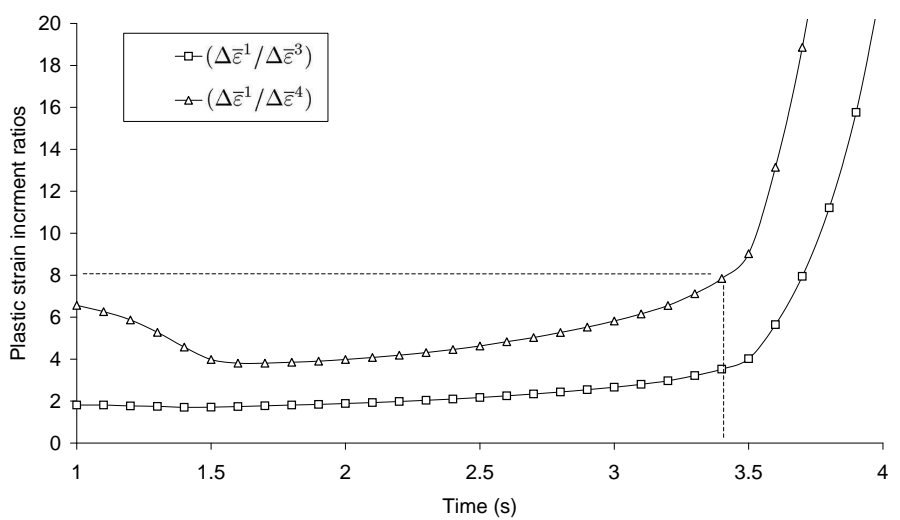

Figure 15. Evolution of the equivalent plastic strain increment ratios $\left(\Delta \bar{\varepsilon}^{1} / \Delta \bar{\varepsilon}^{3}\right)$ and $\left(\Delta \bar{\varepsilon}^{1} / \Delta \bar{\varepsilon}^{4}\right)$.

For the time corresponding to the onset of necking $\left(t_{\text {Bifurcation }}\right)$, the critical values are identified for the two increment ratios. Afterwards, the higher and more sensible ratio $\Delta \bar{\varepsilon}^{1} / \Delta \bar{\varepsilon}^{4}$ will be used and a critical value of 8 seems to be appropriate to detect the onset of the bifurcation point and then the phenomenon of necking (Figure 15). For the time corresponding to the occurence of necking, the numerical limit strain, i.e., the major and minor principal strains are calculated. Moreover, it is found that this critical value is well appropriate for the different speed ratios imposed on the two axes. To cover the whole forming limit diagram, the following speed ratios are tested : 1, 0.75, 
$0.5,0.4,0.25,0.1,0,-0.02,-0.1$ and free for one axis. The forming limit curve identified by use of this criterion is given in Figure 16.

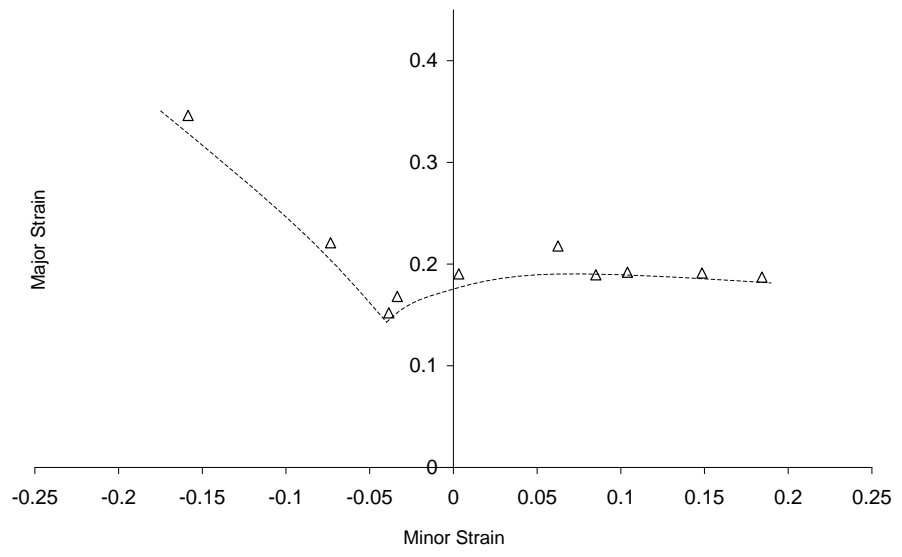

Figure 16. Numerical forming limit curve.

Then, a whole forming limit curve is plotted for this material and we can observe that the FLC is slightly shifted compared to a classical one. Indeed, the minimum of the FLC is not located for a zero value of the minor strain. This well known effect [28] is due to the non-linearity of the strain path at node 1 at the beginning of the test as it can be observed in Figure 17.

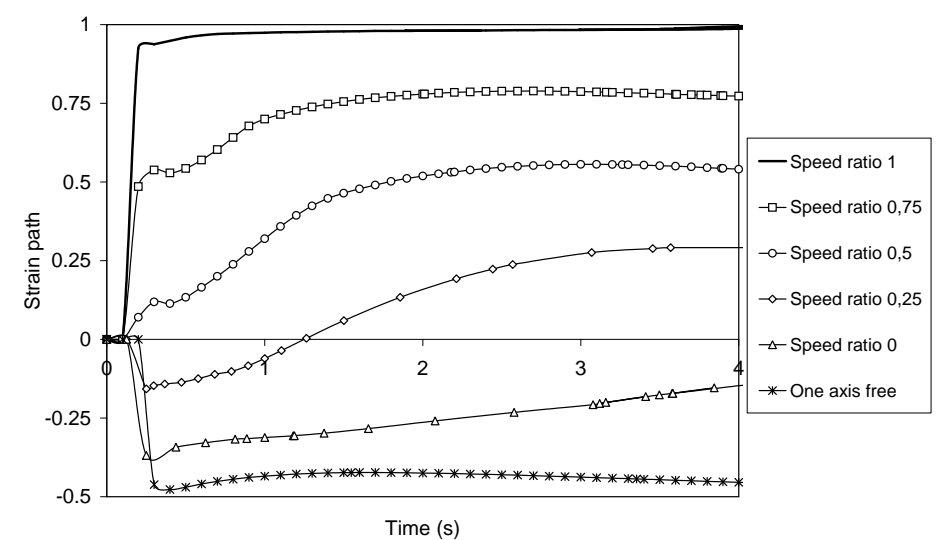

Figure 17. Strain path at node 1 for different speed ratios.

A rigorous method, which can be applied in a numerical or experimental approach, has been constructed in this part and it is proposed to validate it through an experimental campaign on an aluminium alloy dedicated to sheet forming processes. 


\section{Experimental validation}

In this part, after a brief description of the biaxial testing machine and its performances, a comparison between specimen I and specimen II is presented in order to confirm the previous numerical results. Finally, a forming limit curve is experimentally identified for an aluminium alloy 5086.

\subsection{Biaxial testing machine and performances}

The proposed experimental device, presented in Figure 18, is a servo-hydraulic testing machine provided with four independent dynamic actuators allowing biaxial tensile tests on cruciform specimens following two perpendicular axes. For each actuator, the loading capacity is $50 K N$ and the maximum velocity can reach up $2 \mathrm{~m} / \mathrm{s}$. The load on each axis is measured by two specific gage sensors placed between the grip and actuator rod (19).

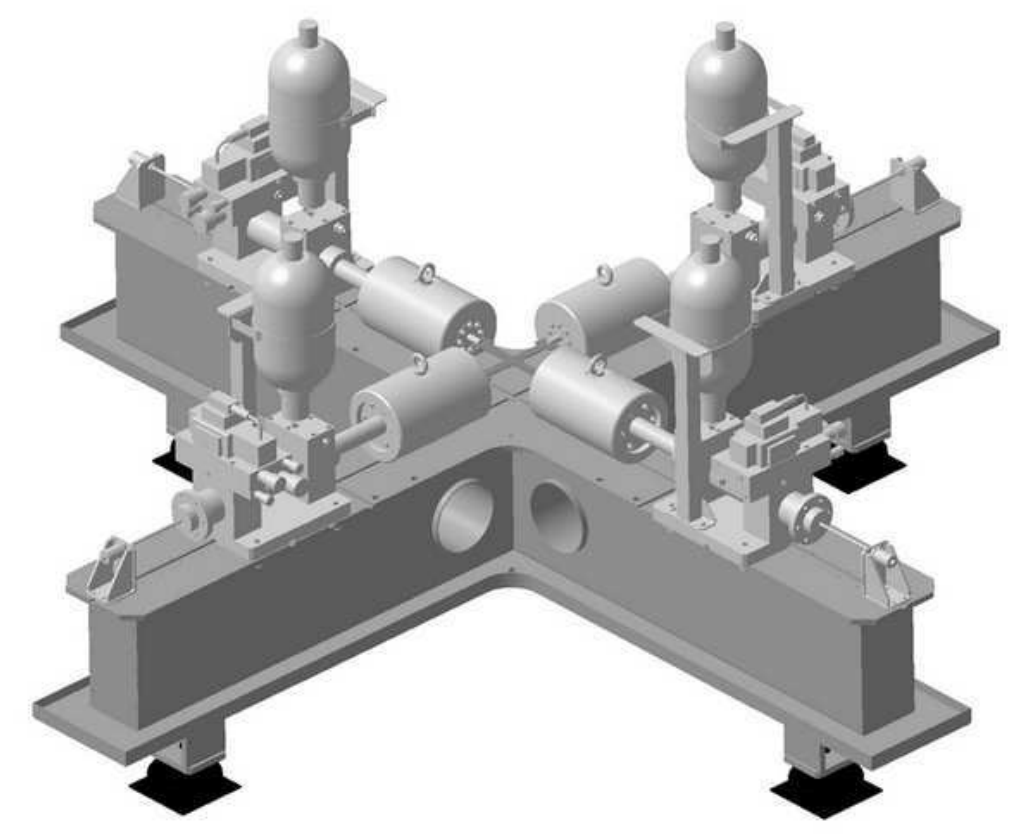

Figure 18. Servo-hydraulic testing machine.

Before the design stage of this machine, one important requirement was the synchronization at impact of the four actuators for which the absolute displacement difference must be less than $0.5 \mathrm{~mm}$. This point is always verified on this machine as illustrated in Figure 20 where the displacement of the central point during test for a specimen tested at a velocity of $1 \mathrm{~m} / \mathrm{s}$ for each actuator is plotted. The trajectory of this point is held in a $0.2 \mathrm{~mm}$ by $0.2 \mathrm{~mm}$ window size. 


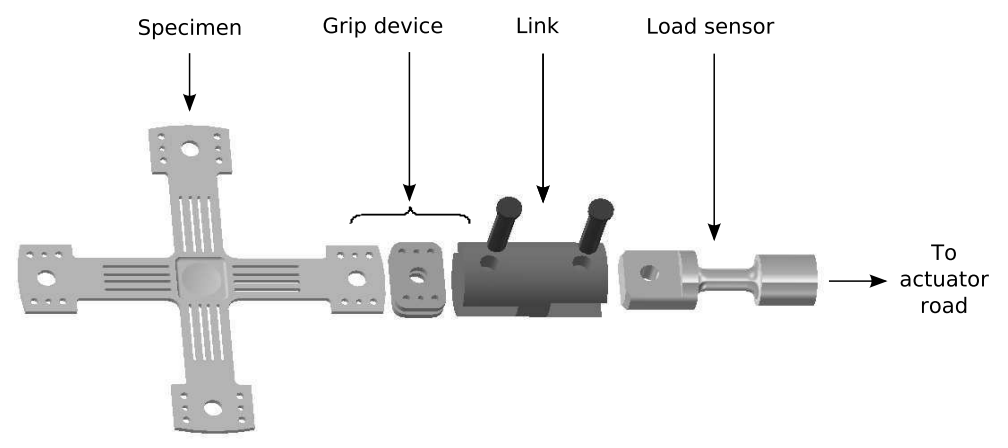

Figure 19. Grip device for each actuator.

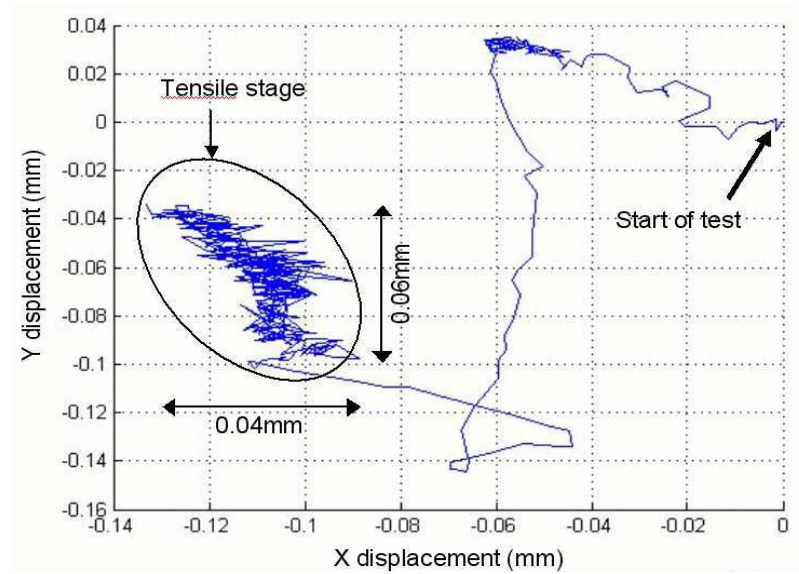

Figure 20. Central point displacement.

\subsection{Strain measurement}

The Digital Image Correlation (DIC) is used to evaluate the strain components during the experiments. To capture the consecutive images during the test, a Fastcam ultima APX-RS digital CMOS camera associated with a macro lens is used. The maximum acquisition rate is $3000 i / s$ for a $1024 \times 1024$ pixels full resolution range. For the specimen geometry defined above, the dimensions of the filmed central zone are about $30 \times 30 \mathrm{~mm}$. A resolution of $512 \times 512$ pixels and an acquisition of $500 \mathrm{i} / \mathrm{s}$ are used during the tests. The DIC technique requires a random speckle pattern so that the image of the specimen could be represented by a discrete function of values depending on grey levels (Figure 21 ). The subset size used here is $32 \times 32$ pixels. The commercial digital imaging program CORRELA2006, developed by LMS at the University of Poitiers, is employed to perform correlation analysis in this work. The DIC program evaluates the surface strains of the specimen.

\subsection{Tests on specimen I and specimen II}

In order to validate the defined shapes of specimen I and specimen II, samples have been manufactured in a rolled aluminium alloy sheet (AA 2017) and a static equi-biaxial test 


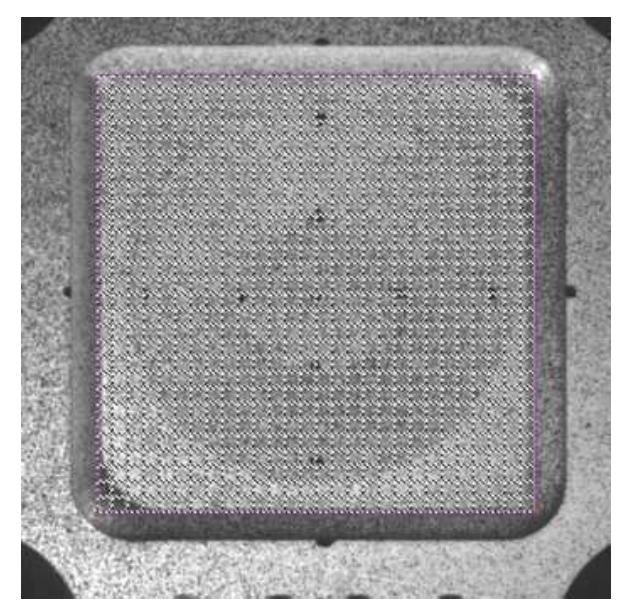

Figure 21. Random speckle pattern and subsets used for the correlation analysis.

has been performed $(1 \mathrm{~mm} / \mathrm{s}$ for each actuator). As expected, necking and then fracture always appear in the transition zone between chamfer and flat central zone for specimen I and at the central point for specimen II (Figure 22).
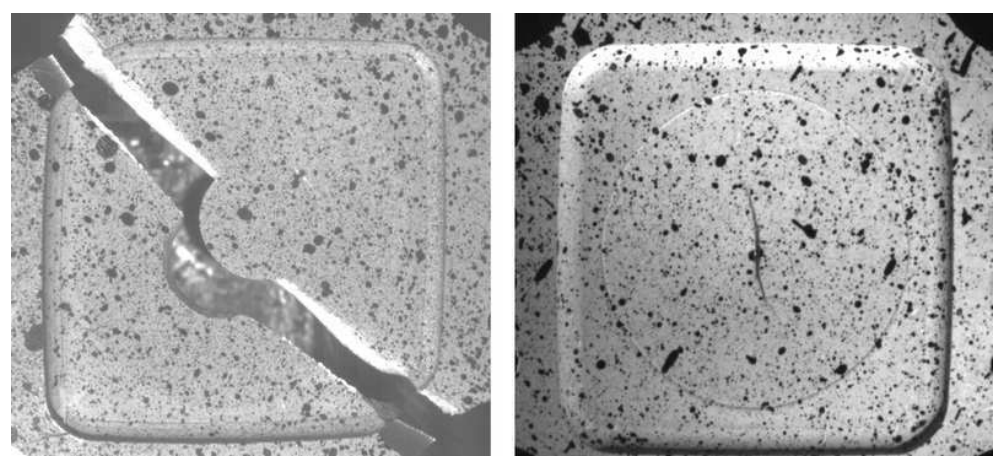

Figure 22. Fracture in specimen I (left) and specimen II.

As presented in the previous numerical study and by use of the DIC technique, the evolution of equivalent plastic strain is measured following the diagonal line of the square central zone for the two specimens (Figure 23). The same conclusions can be drawn, for specimen I, the maximum equivalent plastic strain develops in the transition zone between chamfer and flat central zone.

\subsection{Experimental forming limit curve}

The procedure, presented in paragraph 3.2 for numerical FLC identification, is applied here to detect the experimental limit strains of an aluminium alloy 5086 (Figure 24). The same value of the critical equivalent plastic strain increment ratio is considered. The strain fields on the surface specimen, more particularly in the central zone, are obtained from the DIC technique. The strain thickness is calculated assuming the incompressibility condition during plastic work. Then, an "experimental" equivalent 


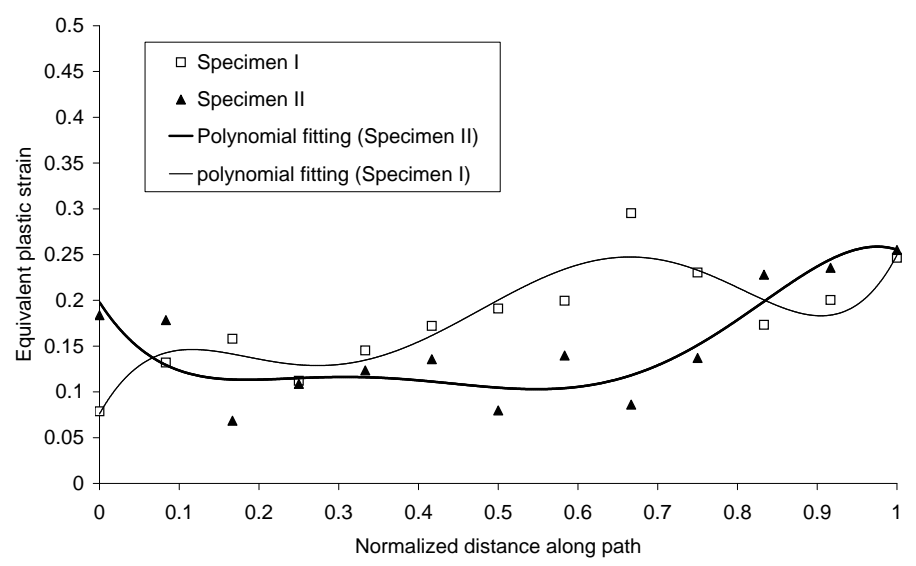

Figure 23. Experimental evolution of the plastic equivalent strain on the diagonal line of specimen I and II square central zone.

plastic strain can be determined. Quasi-static conditions are considered for this first experimental campaign, the main objective was to verify our procedure for a good predicting of the onset of necking. Then, a maximum velocity of $1 \mathrm{~mm} / \mathrm{s}$ is fixed for one axis and for the other one, the velocity varies from free to $1 \mathrm{~mm} / \mathrm{s}$. Figure 25 shows different initial directions of fracture depending on measured strain path but in all cases, the initial stage takes place in the center of the specimen.

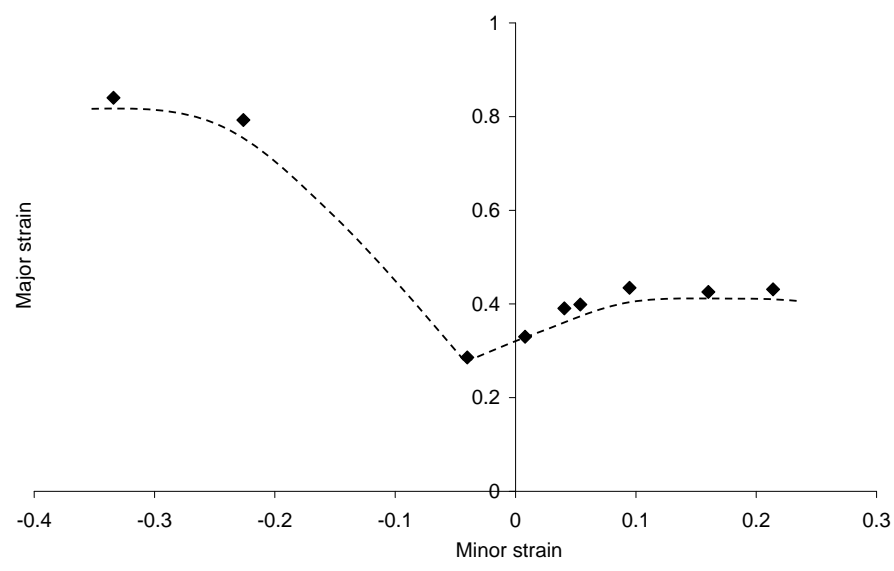

Figure 24. Experimental forming limit curve of AA5086.

For the forming limit curve described in Figure 24, we can observe that the balanced biaxial strain state is not obtained although the corresponding speed ratio has been tested. It means that, for this material, the onset of necking appears in the central zone of the sample but not exactly at the central point. This effect can be explained 


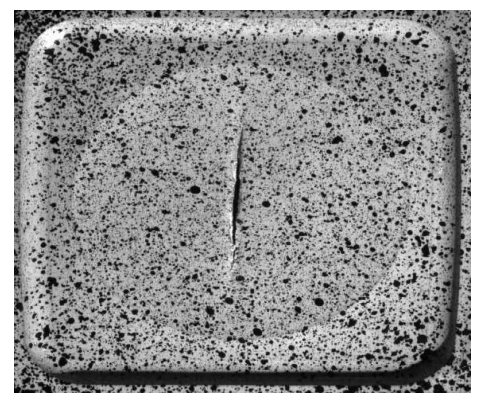

$(-0.23,0.8)$

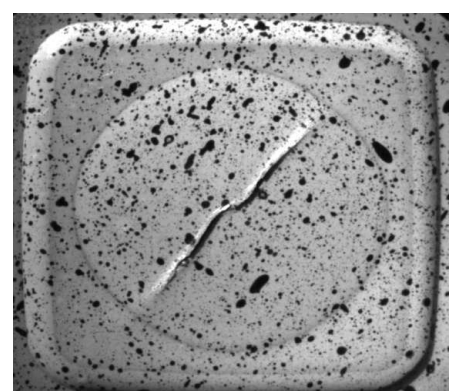

$(0.09,0.43)$

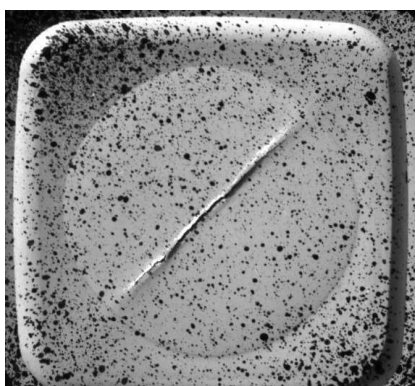

$(0.21,0.43)$

Figure 25. Fracture of specimens for different sets of minor and major strains.

by the anisotropic behaviour of the tested aluminium alloy. In this case, the strain path is slightly different from the path imposed by the velocity ratio of the actuators. The results presented in Figure 24 are in accordance with results from a conventional Marciniak test, developed in parallel (Figure 26). As shown previously, the FLC from the biaxial test is slightly shifted compared to the minimum value of the major strain measured with the Marciniak Test. Nevertheless, the average level of forming limit strains get with the two experimental methods are rather comparable.

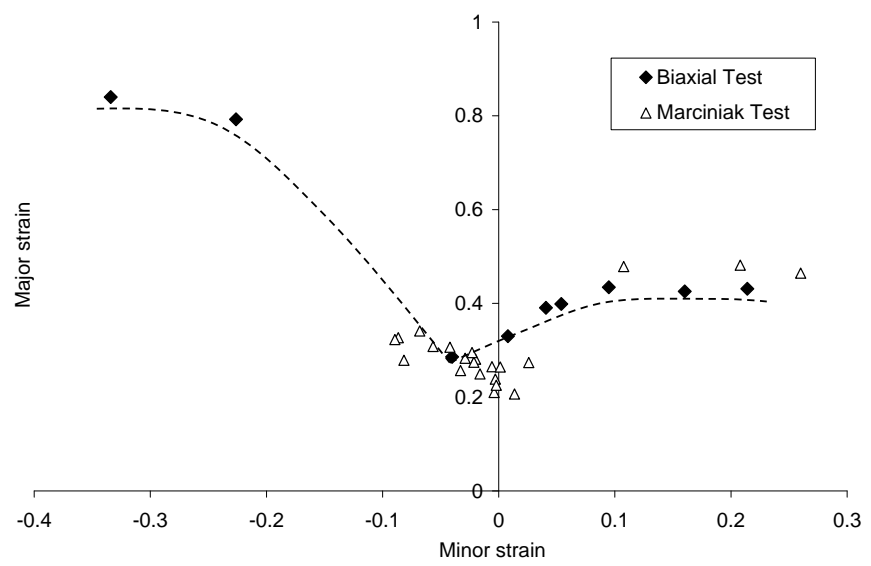

Figure 26. Comparison of Marciniak and biaxial tests for predicting formability of AA5086.

On the other hand, the use of the Marciniak test under dynamic conditions, i.e. with high forming rates, seems rather difficult contrary to our biaxial technique associated with a high speed camera. The influence of forming rate and then strain rate on metal sheet formability will be studied thanks to this new technique. 


\section{Conclusions and Perspectives}

Through numerical FE simulations, various cruciform specimen shapes have been investigated. A parametric study leads to the definition of an efficient shape for which the strain localization appears in the central zone. The numerical approach is validated by experiments on an aluminium alloy AA5086. The onset of necking can be observed and measured in the zone of interest and an experimental forming limit curve is identified thanks to a systematic procedure which can be used both on numerical or experimental results. Compared to classical techniques used in the field of elastoplastic characterization of the metallic sheet behavior, the proposed biaxial experimental device associated with the optimized in-plane cruciform specimen shape presents several advantages:

- The strain path is directly controlled by displacements imposed on each axe of the specimen independently from the specimen shape. Moreover, complex linear and non-linear loading paths can be applied.

- The defined shape leads to very non homogeneous strain and stress fields in the specimen. Material parameters (constants of both hardening law and anisotropic yield criteria) can be identified accurately by means of an inverse analysis associated with the global measurement of forces and displacements and with the local measurement of displacement or strain fields.

- Friction effects have no influence on the results obtained from the proposed rheological test.

- With a single specimen geometry, a complete characterization of both the FLD and rheological behavior can be identified.

- Finally, the experimental device, in the proposed configuration, is well adapted to characterize the whole elasto-plastic behavior of metallic sheets under dynamic biaxial loadings.

Our present works focus on the identification of rheological parameters of hardening laws or yield criteria using the biaxial tensile test presented in this study. This experimental device will be used in the future to study the influence of operating conditions such as temperature and strain rate on formability of sheet metals.

\section{References}

[1] Diot S. Guines D. Gavrus A. Ragneau E. Minimization of friction influence on the evaluation of rheological parameters from compression test : Application to a forging steel behavior identification. Journal of engineering materials and technology, 131:1-10, 2009.

[2] Davoodi B. Gavrus A. Ragneau E. An experimental and numerical analysis of the heat transfert problem in SHPB at elevated temperatures. Institute of Physics Publishing, Measurement Science and Technology, 16:2101-2108, 2005.

[3] Z. Marciniak, K. Kuczynski, and T. Pokora. Influence of the plastic properties of a material on the forming limit diagram for sheet metal in tension. International Journal of Mechanical Sciences, 15:789-805, 1973. 
[4] K. Nakazima, T. Kikuma, and K. Hasuka. Study on the formability of steel sheets. Yamata Technical Report, 264:141-154, 1968.

[5] T.D. Duddedar, F.B. Koch, and E.M. Doeries. Measurement of shapes of foil bulge test samples. experiment mechanics, 17:133-140, 1977.

[6] J.W. Hutchinson, K.W. Neale, and A. Needleman. Mechanics of sheet metal forming, pages 269$285,1978$.

[7] C. Zhang, L. Léotoing, D. Guines, and E. Ragneau. Theoretical and numerical study of strain rate influence on AA5083 formability. Journal of Materials Processing Technology, pages 3849-3858, 2009.

[8] K.J. Pascole and J.W.R. De Villiers. Low cycle fatigue of steels under biaxial straining. Journal of strain analysis, 2(2):117-126, 1973.

[9] D.A. Kelly. Problems in creep testing under biaxial stress systems. Journal of strain analysis, 11:1-6, 1976.

[10] S.B. Lin, J.L. Ding, and H.M. Zbib. Characterization of yield surfaces using balanced biaxial tests of cruciform plate specimen. Scripta metallica material, 28(5):617-622, 1993.

[11] S.B. Lin and J.L. Ding. Experimental study of the plastic yielding of rolled sheet metals with cruciform plate specimen. International journal of plasticity, 11(5):583-604, 1995.

[12] A. Makinde, L. Thibodeau, and K.W. Neale. Development of a apparatus for biaxial testing for cruciform specimens. Exp. Mech., 32:138-144, 1992.

[13] D.E. Green, K.W. Neale, S.R. MacEven, A. Makinde, and R. Perrin. Experimental investigation of the biaxial behavior of an aluminium sheet. International journal of plasticity, 20:1677-1706, 2004.

[14] J.P. Boehler, S. Demmerle, and S. Koss. A new direct biaxial testing machine for anisotropic materials. Exp. Mech., pages 1-9, 1994.

[15] T. Kuwabara, S. Ikeda, and K. Kuroda. Measurement and analysis of differential work hardening in cold rolled steel sheet under biaxial tension. J. Mater. Process. Technol., 80-81:517-523, 1998.

[16] V.P. Naumenko and A.G. Atkins. Engineering assessment of ductile tearing in uniaxial and biaxial tension. Int. J. Fatigue, pages 494-503, 2006.

[17] A. Shimamoto, T. Shimomura, and J. Nam. The development of a servo dynamic loading device. Key Eng. Mater., 243-244:99-107, 2003.

[18] E. Hoferlin, A. Van Bael, P. Van Houtte, G. Steyaert, and C. De Maré. The design of a biaxial tensile test and its use for the validation of cristallographic yield loci. Modelling Simulat. Mater. Sci., 8:423-433, 2000.

[19] D. Mohr and D. Mulalo. Experimental investigation on the plasticity of hexagonal aluminium honeycomb under multiaxial loading. J. Appl. Mech., 71:375-385, 2004.

[20] G. Ferron and A. Makinde. Design and development of a biaxial strength testing device. J. Test. Evaluat., 16:253-256, 1988.

[21] A. Hannon and P. Tiernan. A review of planar biaxial tensile test systems for sheet metal. Journal of materials processing technology, 198:1-8, 2008.

[22] D.R. Hayhurst. A biaxial-tension creep-rupture testing machine. Journal of strain analysis, 8:119$123,1973$.

[23] S. Demmerle and J. Boehler. Optimal design of biaxial tensile cruciform specimens. Journal of mechanics and physics, 41(1):143-181, 1993.

[24] W.M. Johnston, D.W. Pollock, and D.S. Dawicke. Biaxial testing of 2195 aluminium lithium alloy using cruciform specimens. NASA Report CR2002-211942, 2002.

[25] Y. Yong, W. Min, W. Xiang-Dong, and Z. Xian-Bin. Design of a cruciform biaxial tensile specimen for limit strain analysis by FEM. Journal of Materials Processing Technology, 123:64-70, 2002.

[26] S. Zhang and M. Sakane. Multiaxial creep-fatigue life prediction for cruciform specimen. International journal of fatigue, 1:1-9, 2007.

[27] D. Banabic, S. Comsa, P. Jurco, G. Cosovici, L. Paraianu, and D. Julean. FLD theoretical model using a new anisotropic yield criterion. Journal of Material Processing Technology, 157-158:23- 
Development of an in-plane biaxial test for FLC characterization of metallic sheets 23

$27,2004$.

[28] A. Barata Da Rocha, F. Barlat, and J.M. Jalinier. Prediction of the forming limit diagrams of anisotropic sheets in linear and non-linear loading. Materials Science and Engineering, 68:151$164,1984$. 